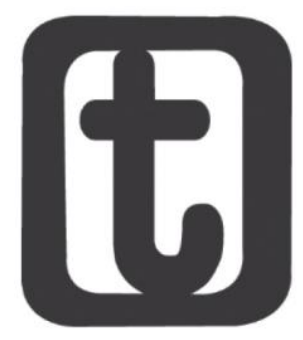

\title{
RACIONALIDADES EM DISPUTA NA FORMAÇÃO EM SERVIÇO SOCIAL NO AMAZONAS
}

\author{
Racionalities in controversy in the social work's education in Amazonas
}

\author{
Roberta Ferreira Coelho de Andrade* \\ https://orcid.org/0000-0002-6535-0760
}

Rayanne Roque Gama**

https://orcid.org/0000-0002-7789-4896

\author{
Tereza Raquel Negreiros do Nascimento Costa*** \\ https://orcid.org/0000-0002-3295-4672
}

\begin{abstract}
RESUMO
Este trabalho discute as racionalidades em confronto na formação profissional em Serviço Social no Estado do Amazonas. Foi desenvolvido a partir da pesquisa bibliográfica e documental, com leitura dos projetos pedagógicos e matrizes curriculares de cursos de Serviço Social ativos no Amazonas. A análise revela a prevalência de instituições privadas na oferta do curso de Serviço Social no Estado do Amazonas, bem como o embate entre o projeto profissional e as demandas do mercado.
\end{abstract}

\section{PALAVRAS-CHAVE}

Amazonas. Formação Profissional. Serviço Social. Currículo. Racionalidades.

\section{ABSTRACT}

This paper discusses the rationalities confronted the Social Work's professional education in Amazonas State. Using bibliographical and documentary research, the pedagogical projects and curricular matrices of active courses of Social Work in Amazonas were read. The analysis reveals the prevalence of private universities that offer Social Work courses in the Amazonas State, as well as the disparities between the professional profile and the demands of the market.

\footnotetext{
* Assistente Social. Doutora e Mestra em Sociedade e Cultura na Amazônia. Professora Adjunta do Departamento de Serviço Social e do Programa de Pós-Graduação em Serviço Social e Sustentabilidade na Amazônia da Universidade Federal do Amazonas. (UFAM, Manaus, Brasil). Av. General Rodrigo Octavio Jordão Ramos, 6200, Coroado, Campus Universitário, Manaus (AM), CEP.: 69080-900. E-mail: roberta_ufam@yahoo.com.br.

** Graduanda em Serviço Social pela Universidade Federal do Amazonas. (UFAM, Manaus, Brasil). Av. General Rodrigo Octavio Jordão Ramos, 6200, Coroado, Campus Universitário, Manaus (AM), CEP.: 69080900. E-mail: rayanne.ufam@gmail.com.

*** Assistente Social. Especialista em políticas públicas em atenção à família. Mestranda em Serviço Social e Sustentabilidade na Amazônia pela Universidade Federal do Amazonas. (UFAM, Manaus, Brasil). Av. General Rodrigo Octavio Jordão Ramos, 6200, Coroado, Campus Universitário, Manaus (AM), CEP.: 69080900. E-mail: raquelcosta83@hotmail.com.
}

DOI 10.22422/temporalis.2020v20n40p94-111

(cc)) BY Commons Atribuição 4.0 Internacional (https://creativecommons.org/licenses/by/4.o/deed.pt_BR), que permite copiar e redistribuir o material em qualquer suporte ou formato, bem como adaptar, transformar e criar a partir deste material para qualquer fim, mesmo que comercial. O licenciante não pode revogar estes direitos desde que você respeite os termos da licença.

Temporalis, Brasília (DF), ano 20, n. 40, p. 94-111, jul./dez. 2020. | ISSN 2238-1856 


\section{KEYWORDS}

Amazonas. Professional education. Social Work. Curriculum. Rationalities.

\section{INTRODUÇÃO}

$\mathrm{N}$ o início de 2020, enquanto escrevíamos este texto, o mundo foi estremecido pela pandemia ocasionada pelo novo coronavírus, ocasião em que, mesmo diante da perda de inúmeras vidas, o capitalismo voraz buscava estratégias de garantir sua própria sobrevivência. As muitas certezas se mostraram incertas, a fortaleza capitalista revelou-se frágil ante um vírus letal, o próprio dinheiro provou-se incapaz de assegurar a vida, evidenciando que a tese defendida no Manifesto do Partido Comunista se mantém muito atual: "Tudo o que era [...] estável se volatiliza, tudo o que era sagrado é dessagrado, e os homens são por fim obrigados a encarar com olhos prosaicos a sua posição na vida, as suas ligações recíprocas" (MARX; ENGELS, 1997, s.p.).

Ainda que o vírus não faça distinção de pessoas e atinja todas as classes sociais, não podemos dizer que impacta todas as classes da mesma forma. Num cenário de morte, salta aos olhos a necropolitica (MBEMBE, 2016), na qual algumas vidas valem mais que outras. Mais uma vez, confirma-se que a história se repete (MARX, 2006) e que, inexoralmente, a luta de classes marca a história da humanidade (MARX; ENGELS, 1997).

A pandemia expôs diante de nossos olhos a correlação de forças entre contrários, o conflito indelével entre capital e trabalho. Se, por um lado, há a preocupação com a defesa incondicional da vida, por outro, exacerba-se a primazia da proteção à economia. Se, por longas décadas, o ideário neoliberal reivindicou o mercado autorregulável e a redução do papel interventor do Estado, num contexto de crise, o mercado se revela cada vez mais incapaz de ser autossuficiente, na medida em que depende das medidas político-econômicas do Estado para subsistir. Aos trabalhadores, o mercado é implacavelmente indiferente, não restando outra alternativa a não ser a proteção social estatal.

O Serviço Social, enquanto profissão que nasce arraigada à dinâmica capitalista, não pode ser indiferente às contradições que permeiam a sociedade e que afetam a vida dos trabalhadores. A todo tempo, ideologias e concepções de mundo duelam na sociedade. As reações à pandemia também nos evidenciam isto. Na formação e no trabalho profissional não é diferente. Nesse processo, a formação profissional tem a responsabilidade de ser mais do que preparação para o emprego, mas uma capacitação científica de um quadro de futuros profissionais em condições de responder às exigências de um projeto profissional, às demandas atuais postas à profissão a partir do mercado de trabalho (IAMAMOTO, 2007).

É bem verdade que, em tempos de avanço do conservadorismo e de supervalorização da lógica tecnicista e pragmática, o projeto de formação do Serviço Social brasileiro se coloca numa perspectiva de contra-hegemonia, nos termos gramscianos, de um esforço hercúleo para manter a fidelidade aos princípios firmados coletivamente pela categoria que apontam para a defesa da liberdade como valor ético fundamental, para o compromisso com a ampliação dos direitos da classe trabalhadora, para a formação e o 
trabalho profissional de qualidade que permitam o alcance dos direitos humanos e sociais e a construção de uma nova ordem societária.

O ocaso do século XX e alvorecer do século XXI nos evidenciou a reconfiguração do cenário educacional no Brasil, inclusive para os cursos de Serviço Social, com ampla atuação do setor mercantil, sobretudo na modalidade a distância. Com isso, a formação profissional é disputada por diferentes racionalidades.

A proposta deste artigo é discutir a formação profissional em Serviço Social no Amazonas, trazendo os projetos pedagógicos dos cursos e as racionalidades neles presentes, que acabam por se mostrar filiados à direção social proposta coletivamente pela categoria - expressa nas Diretrizes Curriculares (ABEPSS, 1996) - ou à racionalidade instrumental demandada pelo mercado ou, mesmo, se trazem elementos mistos.

É uma reflexão que parte da pesquisa financiada pelo Conselho Nacional de Desenvolvimento Científico e Tecnológico (CNPq), sob a responsabilidade do Grupo de Pesquisa Estudos de Sustentabilidade, Trabalho e Direitos na Amazônia (ESTRADAS), vinculado ao Programa de Pós-Graduação em Serviço Social e Sustentabilidade na Amazônia (ESTRADAS) da Universidade Federal no Amazonas (UFAM), que objetivou avaliar a formação profissional em Serviço Social no Amazonas.

Durante o percurso metodológico adotou-se uma abordagem qualiquantitativa, com pesquisa bibliográfica e documental. Num primeiro momento, realizou-se revisão de literatura sobre a temática e, em seguida, procedeu-se à leitura dos projetos pedagógicos das instituições de ensino com autorização para a oferta do curso no estado. Com base em levantamento no sítio eletrônico do Sistema de Regulação do Ensino Superior do Ministério da Educação (e-MEC), no segundo semestre de 2018, 21 instituições estavam ativas para a oferta do curso de Serviço Social, sendo 9 exclusivamente na modalidade presencial, 9 a distância e 3 nas duas modalidades. Destas 21 instituições, tivemos acesso ao projeto pedagógico completo de $52 \%$ delas e das demais $48 \%$ só às matrizes curriculares (quadro de disciplinas e períodos de oferta).

A leitura e a categorização dos documentos se deram à luz das Diretrizes Gerais da Associação Brasileira de Ensino e Pesquisa em Serviço Social (ABEPSS) e das Diretrizes Curriculares do Ministério da Educação (MEC), no intuito de verificar se a formação profissional nestas instituições é conduzida numa perspectiva crítica ou mais mercadológica, ou se há coexistência de racionalidades divergentes.

Para que leitor acompanhe o raciocínio adotado, este artigo faz uma breve contextualização do processo de construção das Diretrizes Gerais da ABEPSS - que são a referência para a análise -, apresenta alguns elementos dos projetos pedagógicos e põe em contraste as racionalidades expressas nos documentos analisados.

Num cenário de crescente empresariamento do ensino superior, de avanço dos interesses mercantis sobre a formação profissional de qualidade e de imposição de uma necropolítica, reconhecemos mais do que nunca a urgência e a necessidade de defesa intransigente do projeto de formação profissional construído como fruto do processo de amadurecimento do Serviço Social Brasileiro, que, acreditamos, se situar no lado certo da história, ou seja, junto aos trabalhadores e trabalhadoras. 
racionalidades em disputa na formação em serviço social no amazonas tompololif

\section{AS DIRETRIZES CURRICULARES COMO REFLEXO DO PROCESSO DE AMADURECIMENTO DO SERVIÇO SOCIAL BRASILEIRO}

As diretrizes curriculares para os cursos de Serviço Social de 1996 -_fruto de um amplo processo de discussão nas unidades de ensino e no seio da categoria nas várias unidades da federação, coordenado pela então Associação Brasileira de Ensino em Serviço Social (ABESS), atualmente Associação Brasileira de Ensino e Pesquisa em Serviço Social (ABEPSS) - expressam o coroamento de uma longa trajetória de avanços, reflexões éticopolíticas, leituras da realidade social, aprofundamentos teórico-metodológicos, crítica e autocrítica da própria profissão.

Bravo et al. (2019), Abramides (2019), Guerra (2016), Maciel (2006) e Sá (1995) nos evidenciam que a formação profissional em Serviço Social tem rupturas e permanências em relação àquela ofertada no seu nascimento em 1936 no Brasil. Ao longo deste caminho, o Serviço Social recebeu diferentes influências teórico-metodológicas e fez sua crítica e autocrítica para, então, como síntese desse processo de maturação, construir um projeto de profissão audacioso e radical nos anos 1990.

lamamoto e Carvalho (2005) explicam que, como resultado da ação social católica, nasceu em 1932 o Centro de Estudos e Ação Social (CEAS), a partir do qual, em 1936, foi fundada a Escola de Serviço Social de São Paulo. De acordo com Maciel (2006), “[...] apesar da ausência de regulamentação da profissão e, portanto, de uma proposta formal para a formação, os currículos dos cursos de Serviço Social apresentavam elementos que constituíam o perfil profissional dos assistentes sociais" (MACIEL, 2006, p. 89-90).

Na leitura de Sá (1995), o perfil profissional era moldado pela vocação e pelos conhecimentos técnicos e morais. O currículo organizado a partir da década de 1930 carregava disciplinas que atendiam a formação teórica básica e a formação técnica. Aguiar (1995) explica que, nas suas primeiras décadas no Brasil, a formação buscava a reforma social e possuía um viés guiado pela doutrina social católica, apoiada na influência norte-americana e no tomismo. Vasconcelos (2010) também percebe a influência da perspectiva higienista, visível em vários currículos das escolas, com disciplinas ligadas à puericultura, higiene, saúde mental etc.

A regulamentação do ensino aconteceu por meio da Lei no 1.889 de 13 de junho de 1953, que dispôs sobre os objetivos do ensino em Serviço Social e as principais matérias a serem ministradas, que aprova, segundo Maciel (2006), o primeiro currículo de Serviço Social do país.

Na década de 1950, o Serviço Social está imerso em um contexto de expansão capitalista no país, demandando um profissional com fundamentos positivistas de reajuste do ser humano à realidade. Maciel (2006) ressalta a manutenção das metodologias de caso, grupo e comunidade.

As décadas de 1960 e 1970 foram cruciais para o currículo de Serviço Social. É a partir deste período que, conforme Netto (2015), se constitui o processo de renovação do Serviço Social por meio de elaborações teóricas referentes à profissão e com o

Temporalis, Brasília (DF), ano 20, n. 40, p. 94-111, jul./dez. 2020. | ISSN 2238-1856 
acirramento do debate teórico-metodológico. Esse processo de renovação da profissão estaria ligado a uma maior inserção profissional nas universidades, com a criação do primeiro curso de pós-graduação em Serviço Social nas Universidade Católicas de São Paulo e Rio de Janeiro (GUERRA, 2011).

Durante a década de 1970, é instituído o segundo currículo de Serviço Social, que traz uma distinção em relação à versão anterior: separação entre teoria e metodologia do Serviço Social e a adoção da Política Social como disciplina obrigatória do currículo (MACIEL, 2006).

A mudança teórico-metodológica do Serviço Social não é e, arriscamos dizer, está longe de ser unânime. Netto (2015) divide esse período de mudança do Serviço Social em três direções: perspectiva modernizadora, reatualização do conservadorismo e intenção de ruptura. Esta última direção faz uma crítica ao tradicional e seus suportes teóricos, metodológicos e ideológicos. A terceira direção tem a pretensão de romper com a herança teórico-metodológica mais conservadora que está enraizada na tradição positivista. Conforme Netto (2015), há um resgate da crítica às tendências de adequação das respostas profissionais às demandas do desenvolvimento capitalista. Para o autor, há um lapso entre a intenção de romper com o conservadorismo e o que poderiam ser os indicativos prático-profissionais que efetivamente consumariam com esta ruptura.

Estas três direções da renovação profissional refletem diretamente nos currículos implementados. Geram-se debates que irão culminar no currículo mínimo aprovado em 1982 pelo Ministério da Educação que simboliza, para lamamoto (2014), o momento de transição, pois nele o Serviço Social volta-se para história, teoria e metodologia do Serviço Social e amarra o trabalho profissional às políticas públicas.

Castro e Toledo (2012) e Netto (2015) indicam que, apesar de apresentar limites nos aspectos teórico-metodológico e técnico-operativo, o currículo de 1982 representou um avanço na direção da tradição marxista e no enfoque da função social da profissão engajada com a efetivação dos direitos, dando base à elaboração do Código de Ética Profissional de 1986.

Bravo et al. (2019) explicitam que, em seu processo de amadurecimento, a profissão decidiu coletivamente, durante a XXVIII Convenção da Associação Brasileira de Ensino em Serviço Social (ABESS), realizar a revisão do currículo de 1982. Assim, foram conduzidas mais de 200 oficinas locais, 25 regionais e 2 nacionais até se aprovar em 1996 as novas Diretrizes Curriculares.

Na década de 1990, para lamamoto (2015), a formação passou a ser guiada pela Lei de Regulamentação da Profissão (Lei № 8.662/93), pelo Código de Ética Profissional do Assistente Social (1993) e pela Proposta de Diretrizes Gerais para o Curso de Serviço Social (1996) da ABESS, que anos depois passaria a ser designada Associação Brasileira de Ensino e Pesquisa em Serviço Social (ABEPSS). É na década de 1990 que se estabelece a relação entre teoria, história e metodologia do Serviço Social. Segundo Abramides e Cabral (2019), 
Social Brasileiro, carinhosamente denominado PEP, que expressa a continuidade do legado construído e conquistado a partir de 1979, do Congresso da Virada, com a direção social da profissão (ABRAMIDES; CABRAL, 2019, p. 48), grifos das autoras).

A proposta das Diretrizes Gerais da ABEPSS estabeleceu o tripé do conhecimento por meio dos núcleos de fundamentação da formação profissional: núcleo de fundamentos teórico-metodológicos da vida social, núcleo de fundamentos da formação sócio-histórica da sociedade brasileira e o núcleo de fundamentos do trabalho profissional. A partir desses núcleos foram definidas as matérias específicas, colocando no centro do currículo o Estágio Supervisionado e o Trabalho de Conclusão de Curso como obrigatórios para obtenção de título de bacharel em Serviço Social. Neste currículo, a relação teoria e prática fica mais evidente e engloba as disciplinas, seminários temáticos, oficinas e laboratórios, e as atividades complementares.

Para lamamoto (2014), apesar de aprovadas por assistentes sociais e pelas instituições organizadoras, as Diretrizes Gerais de 1996 não têm força de lei. As diretrizes legais que orientam a formação profissional em Serviço Social no Brasil são determinadas pela Resolução $n^{\circ} 15$ de março de 2002 do Ministério da Educação (MEC). As diretrizes do MEC são, na verdade, uma expressão dos processos de contrarreforma do ensino superior, moldadas pelo interesse do mercado de trabalho e dos empresários do campo educacional, que desconsideram o debate fomentado pelos encontros e oficinas realizados na década de 1990.

Nesse sentido, o conteúdo curricular passa a ser formulado conforme o interesse de cada instituição de ensino, não sendo possível garantir um conteúdo básico e comum a todos os cursos de Serviço Social no Brasil (IAMAMOTO, 2014). As diretrizes curriculares do MEC (BRASIL, 2002) traçam linhas muito gerais e favorecem o processo de flexibilização da formação profissional em Serviço Social, considerando que as instituições passaram a dispor de maleabilidade para moldar seus projetos pedagógicos conforme seus interesses, muitas vezes até em conflito com as diretrizes da ABEPSS.

\section{RACIONALIDADES EM CONFRONTO NA FORMAÇÃO EM SERVIÇO SOCIAL}

Ao referirmos que o projeto ético-político do Serviço Social brasileiro caminha numa perspectiva contra-hegemônica chamamos à atenção para a imersão da profissão na realidade sócio-histórica, o que não a torna imparcial ou imune aos interesses que duelam por hegemonia na sociedade. Por isso, a formação profissional em Serviço Social também é disputada por projetos antagônicos de sociedade.

As Diretrizes Curriculares assumidas coletivamente pela categoria nos anos 1990 são inspiradas por uma racionalidade que caminha na contramão dos interesses mercadológicos. Este documento, construído a muitas mãos pelos assistentes sociais, é um meio importante para orientação e assimilação dos valores e princípios que norteiam o projeto de formação, entretanto, a vitalidade desse projeto e a adesão pela categoria requerem aos profissionais a entrada e o combate na arena de disputas por hegemonia, na perspectiva postulada por Gramsci (2002). 
Para Guerra (2014), racionalidade não implica em neutralidade. Toda racionalidade está vinculada a um projeto ideológico, refletido a partir de determinada sociedade. Esta racionalidade por si só não define a realidade, mas fornece elementos que ajudam na compreensão e apreensão do que é apresentado naquela realidade.

A razão é, sob justa medida de um estatuto superior, ordenadora, fundante. Sem a capacidade humana da razão (ratio), é pouco provável ou impossível superar a dicotomia entre o mundo e o sujeito cognoscente (HESSEN, 2012). O mundo somente é compreendido se, e somente se, estiver submetido aos estatutos da razão. Na lógica cartesiana, o mundo (ou a forma) se apresenta ou se manifesta como coisa pensante (res cogitans) e como coisa extensa (res extensa). Neste e sob este estatuto, o mundo pode ser compreendido, um sujeito que compreende, que lê o mundo, e uma coisa é compreendida, revelada. Somente pelo uso da razão é possível compreender as manifestações fenomênicas da realidade.

Para Guerra (2014), a racionalidade é parte integrante da razão, pois esta fundamenta-se na razão e se expressa na realidade. Como categoria científica, a racionalidade é aquilo que nos possibilita apreender a unidade objetiva dos processos sociais para então "[...] remetê-los aos marcos do sistema capitalista, apanhar tanto as determinações que se mantêm quanto aquelas que se transformam, as conversões, condições e possibilidades contidas nos processos sociais" (GUERRA, 2014, p. 79).

O pensamento racional está sob um estatuto de universalidade, obedece aos princípios da razão, no entanto, não podemos deixar de admitir que a racionalidade é construída a partir das diversas interpretações da realidade, ou de outra forma, a racionalidade é produto da leitura ou interpretação da realidade a partir dos fundamentos da razão. Logo, assim como coexistem divergentes projetos societários, há racionalidades também distintas e, em alguns casos, em franca oposição.

Com base em Guerra (2014; 2016; 2017), podemos identificar a disputa entre racionalidades quanto à direção da formação e do trabalho profissional. De um lado, um projeto de profissão com viés instrumental à ordem do capital e, de outro, um projeto de horizonte emancipatório. No projeto capturado pela razão instrumental, a autora situa a prevalência de duas racionalidades que se completam: a formal-abstrata e a instrumental. A direção emancipatória é orientada pela teoria social crítica.

No Serviço Social brasileiro, na leitura de Guerra (2016), há uma aproximação à teoria social marxista no contexto de ditatura militar. O marxismo expande-se por toda a América Latina trazendo novas possibilidades e esbarrando em limites. Para a autora, no campo das possibilidades, a conjuntura histórica permite que o Serviço Social questione a neutralidade profissional enraizada pelo Serviço Social Tradicional que possui um caráter conservador. Entre os limites, o marxismo é impregnado pela racionalidade positivista leitura também encontrada em Quiroga (1991) - que leva à compreensão equivocada de que os conceitos teóricos podem aplicar-se na prática.

A abertura do Serviço Social ao marxismo favoreceu debates sobre o conservadorismo, proporcionando à profissão a revisão do Código de Ética Profissional na década de 1990, que busca enfrentar a concepção tecnicista orientada pela racionalidade instrumental (GUERRA, 2016). 
A autora salienta que o projeto profissional que surge com as primeiras escolas de Serviço Social é tomado pela racionalidade instrumental, segundo a qual o perfil profissional é alinhado às demandas do capital. Esse projeto profissional é identificado também por Netto (2015) ao fazer alusão às décadas de 1950 e 1960, com o delineamento do perfil tecnocrático da profissão.

A primeira racionalidade destacada por Guerra (2016) no Serviço Social é a racionalidade instrumental, que permite a manipulação de determinado contexto por meio de questões que afetam o ser social, tais como: aspectos psicossociais, políticos, econômicos, culturais e entre outros, buscando responder com maior efetividade às demandas do padrão societário vigente, o capitalismo.

A segunda razão é a formal-abstrata, responsável pela formalização da profissão e é ilustrada pela busca de um padrão no que se refere a diagnósticos, tratamentos, intervenções, etc., orientada por um referencial positivista (GUERRA, 2016). Na busca pela racionalização técnica, observamos a escolha de estratégias que atinjam aos objetivos-fins, desconsiderando as implicações ético-políticas assumidas pela profissão (GUERRA, 2017).

Ao restringir a profissão a estes tipos de racionalidades, em que a profissão é um instrumento de controle social em favor da sociedade capitalista, nos reduzimos a uma técnica social. Corremos o risco de isolar e fragmentar os fatos apresentados na realidade social, coisificando e neutralizando as possibilidades de que os indivíduos se organizem para transformação da realidade (GUERRA, 2017). As mudanças históricas na divisão sociotécnica do trabalho tornam a profissão suscetível a este tipo de racionalidade que capta o fenômeno pela sua aparência, convertendo e abstraindo aquilo que é mais concreto, e caindo na padronização ou em um modelo de interpretar a realidade, construindo um modo de fazer profissional.

A racionalidade técnica não nasce no sistema capitalista, mas desenvolve-se nele, com o objetivo de controle e dominação dos homens e da natureza. No Serviço Social, a racionalidade técnica ganha espaço por meio da lógica burocrática, pelo controle através dos sistemas de informação - tais como as formas de registro - que visam modelar as políticas sociais, padronizando as respostas. Este tipo de racionalidade técnica não é neutro, uma vez que os instrumentos e técnicas construídos a partir dessa racionalidade possuem referencial teórico e político orientado pelos interesses de classe.

Na ótica de Guerra (2005b), as transformações da profissão exigem uma teoria que permita perceber os dilemas contemporâneos para além de responder demandas emergenciais. O desafio para o Serviço Social é formar profissionais que, mais do que identificar as demandas, sejam capazes de apropriar-se criticamente destas, estando aptos a reconfigurá-las e enfrentá-las de maneira efetiva e eficaz (GUERRA, 2005b). Na articulação entre teoria e prática estão as possibilidades de resposta e transformação da realidade, sob a direção da racionalidade crítica.

Para Guerra (2017, p. 199), ante a tendência imediatista, pragmática, instrumental, é preciso lançar mão da crítica "[...] como arma, esta sim, instrumento de enfrentamento

Temporalis, Brasília (DF), ano 20, n. 40, p. 94-111, jul./dez. 2020. | ISSN 2238-1856 
das racionalidades conservadoras (formal-abstrata e instrumental), as quais se reforçam, se complementam e nos levam a um profundo imobilismo" (GUERRA, 2017, p. 199).

A racionalidade crítico-dialética no Serviço Social resulta da maturação procedida no seio da categoria à luz da teoria social de Marx, a qual inspira o projeto profissional de ruptura. O projeto de formação profissional sintetizado nas Diretrizes Curriculares da ABEPSS de 1996 expressa essa filiação. Para Guerra (2018, p. 25),

\begin{abstract}
A perspectiva crítica que sustenta a formação profissional de assistentes sociais brasileiros (as) considera que são as contradições da realidade que põem e repõem os elementos que historicamente compõem perfis profissionais, requisitando assistentes sociais que sejam contemporâneos(as) do seu tempo, para o que se faz necessária uma formação que seja capaz de responder aos dilemas da atualidade (GUERRA, 2018, p. 25).
\end{abstract}

É óbvio que, por ser uma profissão que nasce como uma necessidade da própria sociedade capitalista, o Serviço Social sempre foi requisitado a responder às demandas do capital. Iamamoto e Carvalho (2005) há muito tempo nos ensinaram que a profissão se fez socialmente necessária e ganhou significado social ao dar respostas às demandas emanadas do capital e do trabalho.

Em seu processo de renovação, nos termos de Netto (2015), a profissão se aproximou da teoria social crítica e fez uma opção teórico-metodológica e ético-política pela direção social crítica, com o compromisso de trabalhar pela consolidação dos direitos sociais, emancipação dos sujeitos e supressão da estrutura de classes. Essa escolha foi muito bem delineada no projeto ético-político do Serviço Social.

Todavia, os anos que se seguem à construção deste projeto são marcados pelo avanço da política neoliberal no Brasil, com a adoção da agenda de privatizações, terceirização e precarização do trabalho, seletividade e focalização na condução das politicas públicas, com a vigorosa progressão da contrarreforma do Estado (BEHRING, 2003), com fortes investimentos públicos na iniciativa privada, inclusive no campo educacional (CISLAGHI, 2012), enquanto o setor público foi progressivamente mais açoitado e sucateado. Com isso, criou-se um cenário extremamente favorável à atuação veemente das empresas educacionais e, mais do que nunca, "[...] o padrão de racionalidade hegemônico e funcional à ordem do capital [...]" (GUERRA, 2017, p. 182) pressiona e é agressivo na sua disputa para sobreposição em relação à racionalidade crítica.

\title{
A FORMAÇÃO EM XEQUE: ENTRE A RACIONALIDADE INSTRUMENTAL E O PROJETO DE FORMAÇÃO
}

O Serviço Social no estado do Amazonas tem uma história de oitenta anos, embora este fato esteja negligenciado na maior parte dos livros que apresentam a historiografia da profissão no Brasil. A criação da Escola de Serviço Social de Manaus ocorreu oficialmente em 1941, ainda que seu funcionamento já ocorresse desde 1940 (MONTENEGRO, 1986).

No segundo lustro da década de 1960, a escola foi incorporada à Universidade do Amazonas (ANDRADE; VALLINA; GAMA, 2020), universidade pública federal, que em 2002 assumiu a denominação de Universidade Federal do Amazonas. Tal universidade se manteve como única ofertante do curso de Serviço Social no estado até 1998, ano que

Temporalis, Brasília (DF), ano 20, n. 40, p. 94-111, jul./dez. 2020. | ISSN 2238-1856 
demarca a abertura da oferta de cursos de Serviço Social à iniciativa privada no estado. Em 2006, obedecendo a tendência nacional, o ensino a distância chega à capital e a vários municípios do interior do estado com a venda da promessa de cursos de graduação em Serviço Social com a mesma qualidade do curso presencial.

O expressivo crescimento do ensino superior privado em Manaus ocorre no primeiro decênio do século XXI. Pereira (2018) salienta que o alargamento do ensino superior em Serviço Social no Brasil nos períodos dos governos de Lula e Dilma Rousseff entre 2003 e 2016 está ligado a programas governamentais de expansão do ensino público, como o Programa de Reestruturação das Universidades Federais (REUNI), e ao forte incentivo do Estado ao setor privado por meio de programas educacionais como o Programa Universidade para Todos (PROUNI) e o Fundo de Financiamento Estudantil (FIES).

No segundo semestre de 2018, segundo levantamento no sítio eletrônico do Sistema de Regulação do Ensino Superior do Ministério da Educação (e-MEC), no segundo semestre de 2018, 21 instituições estavam autorizadas a ofertar o curso de Serviço Social, das quais 9 exclusivamente na modalidade presencial (42,85\%), 9 exclusivamente a distância (42,85\%), e 3 nas duas modalidades (14,3\%). No limiar de 2020, o número de instituições com autorização para oferta do curso saltou para 38, sendo que estavam efetivamente em funcionamento 17, das quais 8 (47\%) na modalidade presencial e $9(53 \%)$ a distância.

Para fins desta análise, tomamos os dados do $2^{\circ}$ semestre de 2018, quando, dentre os cursos presenciais, $22 \%$ estavam na universidade pública federal e $77,78 \%$ na iniciativa privada. As instituições de ensino superior privadas respondiam por todos os cursos ofertados na modalidade a distância. A universidade pública contava e ainda conta com dois cursos de graduação em Serviço Social, sendo um em Manaus e outro em Parintins. Como os cursos dispõem de projetos pedagógicos distintos, foram contabilizados separadamente. Tivemos acesso a $52 \%$ dos projetos pedagógicos e dos demais $48 \%$ apenas à matriz curricular.

Por que tomar os projetos pedagógicos? Não podemos esquecer que, com a Lei de Diretrizes e Bases da Educação Nacional (LDB), Lei nº 9.394 de 1996 (BRASIL, 1996), as instituições de ensino superior (IES) passam a ter o dever de seguir as Diretrizes Curriculares Nacionais para os Cursos de Graduação. Tal lei determina ainda que todas as instituições de ensino devem construir seus Projetos Políticos Pedagógicos (PPP), nos quais definirão suas ações, seus objetivos e meios para atingi-los. As políticas acadêmicas dispostas no PPP das instituições devem ser materializadas no Projeto Pedagógico de Curso (PPC), tornando-se referência das ações e decisões dos cursos. Isto posto, os projetos pedagógicos dos cursos são instrumentos fundamentais à condução do processo formativo.

Ao lermos os projetos pedagógicos dos cursos do Amazonas, identificamos a prevalência da referência às Diretrizes regulamentadas pelo $M E C$, o que responde à exigência legal da LDB. Quanto às diretrizes curriculares da Associação Brasileira de Ensino e Pesquisa em Serviço Social (ABEPSS) de 1996, identificamos a alusão em $55 \%$ dos projetos dos cursos presenciais e em apenas $11 \%$ daqueles ofertados na modalidade a distância. Não podemos esquecer que os projetos pedagógicos carregam em si as opções ideológicas das instituições para a condução da formação profissional. 
Dentre as instituições de ensino, somente a universidade pública é filiada à ABEPSS. Talvez, até por isso mesmo, averiguamos que a maior correspondência às Diretrizes Curriculares da ABEPSS está em 22,22\% dos projetos pedagógicos dos cursos presenciais, que pertencem aos cursos da IES pública. Neles, constatamos maior articulação do tripé ensino, pesquisa e extensão, indicação dos mesmos princípios e diretrizes, incluindo as dimensões teórico-metodológica, ético-política e técnico-operativa como essenciais à formação profissional, proposição de ensino teórico-prático, organização das disciplinas por núcleos de fundamentação, previsão de desenvolvimento de trabalho de conclusão de curso em forma monográfica após pesquisa científica, dentre outras questões. Ao orientar a formação e as disciplinas por meio dos Núcleos de Fundamentos da ABEPSS, a instituição se posiciona comprometida com a formação profissional de qualidade. Nestes projetos, identificamos forte presença da racionalidade crítica, que pressupõe análise crítica da realidade e articulação teórico-prática.

Das 7 instituições privadas com cursos presenciais, encontramos em $86 \%$ dos projetos indícios de uma racionalidade crítica, considerando o perfil de egresso, os objetivos do curso, os princípios expressos nestes documentos e as ementas de algumas disciplinas. Há uma proposição de uma condução crítico-reflexiva, com obediência aos princípios ético-políticos da profissão, que favoreça a formação de profissionais éticos, propositivos, reflexivos. Além disso, vimos um espaço importante dedicado aos fundamentos históricos e teórico-metodológicos, à política social, à questão social, ao trabalho como categoria ontológica, à pesquisa e ao estágio. Em 14\% identificamos a referência literal à adoção de uma perspectiva de transformação social.

Em contrapartida, nas IES privadas estão os maiores indicativos de uma preocupação com um processo formativo mais técnico-instrumental, inclusive sinalizando para uma visão de instrumentalidade restrita à "aplicabilidade" de métodos e técnicas. Nas diretrizes da ABEPSS (1996) podemos perceber uma leitura de instrumentalidade que transcende os instrumentais técnicos, pois expressam uma compreensão de que a capacitação teóricometodológica e ético-política é condição necessária para o desenvolvimento da capacitação técnico-operativa.

Guerra (2014) esclarece que a instrumentalidade é uma capacidade constitutiva da profissão, que se constrói e se reconstrói no processo sócio-histórico; é “[...] mediação, por onde passam as teorias, os valores, princípios que determinam a escolha dos instrumentos, das técnicas, das estratégias e das táticas" (GUERRA, 2016, p. 301). Por isso, seu debate não pode ser deslocado dos fundamentos históricos e teóricometodológicos do Serviço Social.

Quanto ao trato da relação teórico-prática nas IES privadas, vimos que há muitas pistas que apontam para a racionalidade instrumental, no sentido de uma formação moldada pelo ensino de técnicas e de instrumentais com pouca reflexão crítica, o que diverge da orientação da ABEPSS (1996; 2010), que defende a transversalidade do ensino da prática (SANTOS; PINI, 2013) ou ensino teórico-prático, nos termos de Guerra (2005a), devendo permear todo o percurso formativo (disciplinas, pesquisa, extensão, atividades complementares etc.), que tem no estágio supervisionado um de seus componentes fundamentais. 
Apesar desta proposta de transversalidade, ainda vimos em 54,54\% dos 11 projetos pedagógicos completos aos quais tivemos acesso uma ênfase ao estágio enquanto "momento da prática ", "experiência de exercício profissional”, "realização de atividades práticas", "aprendizagem da intervenção". Em 9,1\% fala-se em "integração" de teoria e prática, uma concepção que nos parece positivista. Em 36,36\% há uma compreensão do estágio numa perspectiva mais dialética, enquanto momento privilegiado da relação teórico-prática.

Em 90,47\% do total de 21 instituições (incluindo projetos pedagógicos e matrizes curriculares), que dizem respeito àquelas de iniciativa privada, foram reconhecidas disciplinas específicas voltadas para o propalado "ensino da prática" profissional, dentre as quais podemos citar: Oficinas de Prática, Orientação para a Prática Profissional, Instrumentos técnico-operativos do Serviço Social, Oficina de instrumentos técnicooperativos; Oficina de identidade e formação profissional, Comunicação na Prática do Assistente Social, Oficina de Instrumentalidade, Seminários de Prática e Laboratórios de Prática.

Chama a atenção também a oferta de disciplinas em $42,85 \%$ das IES que se distanciam sobremaneira das Diretrizes da ABEPSS, como Empreendedorismo, Teologia, Planejamento de Carreira e Sucesso Profissional, Desenvolvimento Pessoal e Trabalhabilidade, Empregabilidade, dentre outras similares. Em 23,8\% das IES vimos disciplinas de Informática ou Tecnologia da Informação, o que possivelmente se inspira nas diretrizes do MEC (BRASIL, 2002), que indicam a necessidade de o egresso de Serviço Social ter domínio da informática.

No ensino a distância, visualizamos questões incompatíveis com o projeto profissional em relação à condução da formação em 55,55\% das IES que ofertam curso nesta modalidade - como: fragmentação de conteúdos, repartição de história, teoria e metodologia, trato de gestão e planejamento como elementos dissociados, preocupação extremada com a prática ou a aplicação da teoria e com a garantia da empregabilidade. Para exemplificar, citamos uma IES que tem em sua matriz 4 disciplinas dedicadas aos Fundamentos Históricos e Teórico-Metodológicos do Serviço Social, sendo a primeira destinada à dimensão histórica, a segunda e a terceira direcionadas à dimensão teórica, com o grifo ao positivismo e ao marxismo, enquanto a última é reservada à dimensão metodológica. Essa fragmentação foi identificada e criticada no currículo mínimo de 1982 e superada com a revisão curricular procedida em 1996. Então, apesar de usar a nomenclatura de Fundamentos Históricos e Teórico-Metodológicos do Serviço Social, como está nas diretrizes da ABEPSS de 1996, a condução dada pela IES é totalmente equivocada, fragmentada, descontextualizada.

A racionalidade instrumental que ganha espaço no Serviço Social ofertado na modalidade a distância preocupa-se com o conhecimento que é medido pela capacidade de resposta a uma ação. O resultado desse conhecimento é sua capacidade de produzir respostas imediatas em conformidade com as exigências do mundo burguês (GUERRA, 2013).

A formação profissional na universidade pública não está imune a elementos da racionalidade instrumental, visto que o projeto pedagógico é resultado de uma teleologia, que expressa uma direção e um horizonte intencionalmente pensados, 
gestados, escritos, mas sua materialização depende de homens e mulheres. No seio da universidade pública, também se sente um anseio de uma pequena fração dos discentes, docentes e supervisores de campo por mais prática na formação, o que requer vigilância no sentido de não se recair no pragmatismo ou ativismo, ao mesmo instante em que não se pode tender ao teoricismo.

Além disso, não temos o direito de esquecer que a universidade pública é atravessada por interesses diversos, econômicos, políticos e sociais. Neste sentido, é preciso ter clareza de que não é possível se pensar ou mesmo construir o processo de mudança de caminhos dos projetos de formação sem levar em conta esses interesses. Não podemos ignorar, por exemplo, que, em tempos de contingenciamento dos gastos públicos, há um crescente sucateamento das instituições públicas, ainda mais após a Emenda Constitucional $\mathrm{n}^{\circ} 95$ de 16 de dezembro de 2016. Com isso, pesquisa e extensão - espaços fundamentais de reflexão/ação, de práxis - dispõem de recursos mais escassos e muitos pesquisadores são seduzidos a submeter suas pesquisas aos patrocínios do mercado. Os concursos públicos são parcos ou inexistentes e, com isso, intensificam-se as demandas e precarizam-se as condições de trabalho. Nesse cenário, como garantir uma formação de qualidade? Como oferecer uma formação ampla, com acesso a ensino, pesquisa e extensão sem recursos, sem as condições objetivas para tal? Por isso, mais do que um desejo ou esforço pessoal dos docentes e discentes, a formação depende das políticas institucionais, pois, como nos ensinou Marx (2006): "Os homens fazem sua própria história, mas não a fazem como querem; não a fazem sob circunstâncias de sua escolha e sim sob aquelas com que se defrontam diretamente, legadas e transmitidas pelo passado" (MARX, 2006, p. 7).

Chauí (2014) destaca que o modelo de universidade vigente nas instituições de ensino a partir da ditadura militar alinha-se com a perspectiva fordista de produção, com menor reflexão, com vistas à constituição de mão de obra qualificada, que possa ser absorvida pelo mercado de trabalho. A expansão do ensino superior ao longo das décadas não implica na formação de qualidade, nem que esta formação garantirá a entrada no mercado de trabalho. Por isso, a autora explica que as universidades são movidas por uma ideologia da competência, justificando e reproduzindo a manutenção do sistema social vigente na medida em que se adequam ao modelo autoritário e hierarquizado.

lamamoto (2014) sinaliza a tendência a um ensino superior centrado na formação por competências. Essas competências são tratadas como o "motor para o desenvolvimento", fazendo com que o compromisso das instituições seja voltado às inovações que respondam às necessidades econômicas do mercado. Chauí (2014) denuncia a partir da "ideologia da competência" a fragmentação social do trabalho, na qual se separam aqueles que são competentes, portanto, possuem o saber, e aqueles que não são, sendo incompetentes e destinados a executar. Esta ideologia reafirma a divisão social e oculta as divisões políticas, econômicas e culturais.

Na medida em que esse discurso de competência se enraíza na sociedade, o valor dado às pessoas depende das suas qualificações, das suas credenciais; como consequência, os indivíduos passam a competir entre si. A ideologia da competência não está presente somente na busca pela formação profissional universitária, mas também na forma como a universidade volta seu espaço e sua pesquisa para a obtenção do diploma, bem como para as exigências do capital. Podemos observar esta ideologia no mercado de trabalho, 
no qual aquele que possui qualificação, em tese, teria acesso a este. Entretanto, o que vemos, apesar do discurso mercantilizado pregado pelas corporações educacionais, é a formação de um exército de reserva que estaria apto para atuar em suas áreas de graduação, mas que não encontra espaço de trabalho.

Isto posto, em tempos de defesa da ideologia da competência, de luta por hegemonia de uma racionalidade instrumental e de emergência de uma onda neoconservadora ${ }^{1}$, mais do que nunca o projeto profissional do Serviço Social é desafiado a manter seu vigor na ruptura com o conservadorismo, tendo claro que há racionalidades divergentes em contínuo conflito, a duelar por hegemonia na formação profissional em Serviço Social.

\section{CONSIDERAÇÕES FINAIS}

A discussão feita ao longo deste texto enfatiza que a sociedade é atravessada por projetos societários antagônicos, imbuídos de racionalidades que duelam por hegemonia. Na formação profissional em Serviço Social não é diferente, inclusive no Amazonas. Há um projeto emancipatório, de racionalidade crítica, ao qual se filiam as Diretrizes Curriculares da ABEPSS, que é confrontado por um projeto societário conservador, que intenciona conservar a ordem capitalista e, para tanto, por meio de uma racionalidade instrumental, busca aligeirar a formação profissional, tornando-a mais pragmática e menos reflexiva.

Em plena pandemia, vemos que a ânsia capitalista de acumulação e preservação da economia se mantém, numa agenda que concorre com a preservação da vida, deixando subentendido que ceifar vidas dos trabalhadores é um preço a ser pago para que o sistema capitalista volte à sua "normalidade".

Este cenário nos evidencia, mais do que nunca, que é fundamental que o projeto éticopolitico do Serviço Social seja elemento fundante da formação profissional, para que esta fortaleça seu compromisso na direção crítica, que nos aproxima do projeto social emancipatório.

\section{REFERÊNCIAS}

ABEPSS. Diretrizes gerais para o curso de Serviço Social. Rio de Janeiro. Novembro, 1996. Disponível em:

http://www.abepss.org.br/arquivos/textos/documento_201603311138166377210.pdf.

Acesso em: 5 abr. 2020.

. Política Nacional de Estágio da Associação Brasileira de Ensino e Pesquisa em Serviço Social. 2010. Disponível em:

http://www.cfess.org.br/arquivos/pneabepss_maio2010_corrigida.pdf. Acesso em: 15 mar. 2020.

ABRAMIDES, M. B. C. O projeto ético-político do Serviço Social brasileiro: ruptura com o conservadorismo. São Paulo: Cortez, 2019.

${ }^{1}$ Ver SIMIONATTO, 2019. 
ABRAMIDES, M. B. C.; CABRAL, M. S. R. 40 anos do "Congresso da Virada". In: SILVA, M. L. O. (Org.). Congresso da virada e o Serviço Social hoje: reação conservadora, novas tensões e resistências. São Paulo: Cortez, 2019, p. 35-55.

AGUIAR, Antônio Geraldo de. Filosofia e Serviço Social: das origens a Araxá. 5.ed. São Paulo: Cortez; Piracicaba. SP: Universidade Metodista de Piracicaba, 1995.

ANDRADE, Roberta Ferreira Coelho de; VALLINA, Marcelo Mario; GAMA, Rayanne Roque. Da Escola de Serviço Social de Manaus ao boom do mercado educacional no Amazonas. In: ANDRADE, Roberta Ferreira Coelho de; VALLINA, Marcelo Mario. Novos contornos do Serviço Social no Amazonas. Boa Vista: Editora da UFRR, 2020, p. 25-41.

BEHRING, Elaine Rossetti. Brasil em contra-reforma: desestruturação do Estado e perda de direitos. São Paulo: Cortez, 2003.

BRASIL. Lei Nº 9.394 de 20 de dezembro de 1996. Estabelece as diretrizes e bases da educação nacional. Disponível em: http://www.planalto.gov.br/ccivil_03/Leis/L9394.htm. Acesso em: 10 abr. 2020.

. Ministério da Educação. Resolução CNE/CES 15, de 13 de março de 2002. Disponível em: http://portal.mec.gov.br/cne/arquivos/pdf/CES152002.pdf. Acesso em: 31 mar. 2020.

BRAVO, M. I. S. et al. O protagonismo da ABESS/ABEPSS na virada da formação profissional em Serviço Social. In: SILVA, M. L. O. (Org.). Congresso da virada e o Serviço Social hoje: reação conservadora, novas tensões e resistências. São Paulo: Cortez, 2019, p. 56-82.

CASTRO, Marina Monteiro de Castro e. TOLEDO, Sabrina Navarro. A reforma curricular do Serviço Social de 1982 e sua implantação na faculdade de Serviço Social da Universidade Federal de Juiz de Fora. Libertas. Revista da faculdade de serviço Social - Programa de Pós-graduação em Serviço Social. v. 11. n. 2. 2012.

CHAUÍ, Marilena. A ideologia da competência. São Paulo: Fundação Perseu Abramo/Autêntica, 2014 (Escritos de Marilena Chauí, 3).

CISLAGHI, Juliana Fiuza. Financiamento do ensino superior no Brasil: novos e antigos mecanismos de privatização do fundo público. In: SALVADOR, Evilasio et. al. (orgs.). Financeirização, fundo público e política social. São Paulo: Cortez, 2012, p. 261-284.

GRAMSCI, A. Cadernos do Cárcere. vol. 5. Rio de Janeiro: Civilização Brasileira, 2002.

GUERRA, Y. A instrumentalidade do Serviço Social. 10. ed. São Paulo: Cortez, 2014.

GUERRA, Y. A pós-graduação em Serviço Social no Brasil: um patrimônio a ser preservado. Temporalis. Brasília (DF), ano 11, n 22, p. 125-158. jul./dez. 2011. Disponível em: http://portaldepublicacoes.ufes.br/temporalis/article/viewFile/2141/1607. Acesso em: 15 fev. 2020. 
GUERRA, Y. Consolidar avanços, superar limites e enfrentar desafios: os fundamentos de uma formação profissional crítica. In: GUERRA, Y. et al. Serviço Social e seus fundamentos: conhecimento e crítica. Campinas: Papel Social, 2018, p. 25-46.

GUERRA, Y. Expressões do pragmatismo no Serviço Social: reflexões preliminares. Revista Kátal. Florianópolis, v. 6, n. esp., p. 39-49. 2013. Disponível em: http://www.scielo.br/pdf/rk/v16nspe/04.pdf. Acesso em: jul. 2019.

GUERRA, Y. Nas pegadas dos 80 anos de história do Serviço Social: o debate da instrumentalidade como marco. In: SILVA, M. L. O. Serviço Social no Brasil: história de resistências e de ruptura com o conservadorismo. São Paulo: Cortez, 2016, p. 287-309.

GUERRA, Y. No que se sustenta a falácia de que "na teoria a prática é outra?". 2 Seminário Nacional Estado e Políticas Sociais no Brasil. 2005. Disponível em: http://cacphp.unioeste.br/projetos/gpps/midia/seminario2/trabalhos/servico_Social/mss2o .pdf. Acesso em: 28 fev. 2020.

GUERRA, Y. O Potencial do Ensino Teórico-Prático no Novo Currículo: elementos para o debate. Katálysis, Florianópolis/SC, v.8. n.2. jul./dez. 2005. p. 147- 154.

GUERRA, Y. Racionalidades e Serviço Social: o acervo técnico-instrumental em questão. In: SANTOS, C.M; BACKX, S.; GUERRA, Y. A dimensão técnico-operativa no Serviço Social: desafios contemporâneos. 3. ed. São Paulo: Cortez, 2017, p. 181-201.

HESSEN, J. Teoria do Conhecimento. 4. ed. São Paulo: Martins Fontes, 2012.

IAMAMOTO, Marilda Villela. A formação acadêmico-profissional no Serviço Social brasileiro. Serviço Social e Sociedade, São Paulo, v. 120, p. 609-639, out./dez. 2014. Disponível em: http://www.scielo.br/pdf/sssoc/n120/02.pdf. Acesso em: 5 abr. 2020.

IAMAMOTO, M. V. O serviço Social na contemporaneidade: trabalho e formação profissional. 26. ed. São Paulo: Cortez, 2015.

IAMAMOTO, M. V. Renovação e conservadorismo no serviço social. 9. ed. São Paulo: Cortez, 2007.

IAMAMOTO, M. V.; CARVALHO, R. Relações sociais e Serviço Social no Brasil: esboço de uma interpretação histórico-metodológica. 17. ed. São Paulo: Cortez, 2005.

MACIEL, A. L. S. Universidade em crise: uma travessia necessária para a formação em Serviço Social. 2006. 220f. Tese (Doutorado em Serviço Social) - Faculdade de Serviço Social, Pontifícia Universidade Católica do Rio Grande do Sul. Porto Alegre, 2006.

MARX, K; ENGELS, F. Manifesto do Partido Comunista. 2. ed. Lisboa: Edições Avante!, 1997.

MARX, K. O Dezoito Brumário de Louis Bonaparte. São Paulo: Centauro, 2006. 
MBEMBE, A. Necropolítica. Arte \& Ensaios. n. 32, dez. 2016, p. 122-151. Disponível em: https://revistas.ufrj.br/index.php/ae/article/view/8993. Acesso em: 5 abr. 2020.

MONTENEGRO, Rita. A criação da Escola de Serviço Social de Manaus. 1986. 154 f. Dissertação (Mestrado em Serviço Social) - Departamento de Serviço Social, Pontifícia Universidade Católica do Rio de Janeiro. Rio de Janeiro, 1986.

NETTO, José Paulo. Ditadura e serviço Social: uma análise do Serviço Social no Brasil pós64. 17. ed. São Paulo: Cortez, 2015.

PEREIRA, Larissa Dahmer. Expansão dos cursos públicos de Serviço Social entre os anos de 2003 e 2016: desafios para a formação profissional. Revista Kátal. Florianópolis, v. 21, n. 1, p. 189-199, jan./abr. 2018.

QUIROGA, Consuelo. Invasão positivista no Marxismo: manifestações no ensino da Metodologia no Serviço Social. São Paulo: Cortez, 1991.

SÁ, Jeanete Liasch Martins de. Conhecimento e Currículo em Serviço Social: análise das contradições (1936 - 1975). São Paulo. Cortez, 1995.

SANTOS, C.; PINI, A. Transversalidade do ensino da prática na formação profissional do assistente social e o Projeto ABEPSS Itinerante. Temporalis, Brasília (DF), ano 13, n. 25, p. 133-153, jan./jun. 2013.

SIMIONATTO, I. Serviço Social, reação conservadora e o ataque ao marxismo. In: SILVA, M. L. O. (Org.). Congresso da virada e o Serviço Social hoje: reação conservadora, novas tensões e resistências. São Paulo: Cortez, 2019, p. 117-134.

VASCONCELOS, E. M. (org.). Saúde Mental e Serviço Social: o desafio da subjetividade e da interdisciplinaridade. São Paulo: Cortez, 2010. 
Roberta Ferreira Coelho de Andrade Trabalhou concepção e delineamento; análise e interpretação dos dados; redação do artigo, revisão crítica e na aprovação da versão a ser publicada.

Assistente Social, Professora Adjunta do Departamento de Serviço Social e do Programa de Pós-Graduação em Serviço Social e Sustentabilidade na Amazônia da Universidade Federal do Amazonas, Doutora e Mestra em Sociedade e Cultura na Amazônia pela Universidade Federal do Amazonas, Líder do Grupo de Pesquisa Estudos de Sustentabilidade, Trabalho e Direitos na Amazônia (ESTRADAS).

Rayanne Roque Gama Trabalhou concepção e delineamento; análise e interpretação dos dados; redação do artigo, revisão crítica.

Graduanda em Serviço Social pela Universidade Federal do Amazonas, Membro do Grupo de Pesquisa Estudos de Sustentabilidade, Trabalho e Direitos na Amazônia (ESTRADAS).

Tereza Raquel Negreiros do Nascimento Costa Trabalhou concepção e delineamento; análise e interpretação dos dados; redação do artigo, revisão crítica.

Assistente Social. Especialista em políticas públicas em atenção à família. Mestranda em Serviço Social e Sustentabilidade na Amazônia pela Universidade Federal do Amazonas. 